\title{
Children's Elementary School Social Experience and Executive Functions Development: Introduction to a Special Section
}

\author{
Pol A. C. van Lier ${ }^{1} \cdot$ Kirby Deater-Deckard ${ }^{2}$
}

Published online: 21 December 2015

(C) Springer Science+Business Media New York 2015

\begin{abstract}
Children's executive functions, encompassing inhibitory control, working memory and attention are vital for their self-regulation. With the transition to formal schooling, children need to learn to manage their emotions and behavior in a new and complex social environment that with age increases in the intensity of social interactions with peers and teachers. Stronger executive functions skills facilitate children's social development. In addition, new experiences in the social environments of school also may influence executive function development. The focus of this special section is on this potential impact of elementary school social experiences with peers and teacher on the development of children's executive functions. The collection of papers encompass various aspects of peer and teacher social environments, and cover broad as well as specific facets and measures of executive functions including neural responses. The collection of papers sample developmental periods that span preschool through mid-adolescence. In this introduction, we summarize and highlight the main findings of each of the papers, organized around social interactions with peers and interactions with teachers. We conclude our synopsis with implications for future research, and a specific focus on prevention and intervention.
\end{abstract}

Pol A. C. van Lier

pac.van.lier@psy.vu.nl

1 Department of Developmental Psychology, Vrije Universiteit Amsterdam, Amsterdam, the Netherlands

2 Department of Psychological and Brain Sciences, University of Massachusetts Amherst, Amherst, MA, USA
It is with great pleasure that we introduce this special section on the impact of "Children's School Social Experiences and Executive Function Development". The kindergarten and elementary school period is a critically important period of development for children. During these years, which in western industrial societies generally span 4-12 years of age, children make the transition from spending much of their time in their homes and neighborhoods, into school settings that require them to function in the formal setting of classrooms for extended periods of time every day. Indeed, although many young children in western industrial cultures attend daycare programs before entering formal schooling, the social environment in daycare is importantly different from elementary school (Ladd, Herald, \& Kochel, 2006). In school, children have to function in homogeneous age groups which increases the pressure to succeed among age mates, and the standards for academic performance and behavioral self-control increase with each school grade. At the same time, the frequency and duration of interactions with peers increases dramatically compared to daycare, given the lower adult/child ratio in school compared to daycare and home settings. Moreover, the role of the teacher shifts from being primarily a caregiver in daycare, to being a supervisor, instructor, and evaluator of academic skill development.

The new social environment of the school classroom provides children with valuable experiences to learn and practice social and emotional skills, to develop friendships with peers, and to understand important social rules related to working with teachers as authority figures. However, this new social environment also comes with risk. For instance, in any given school grade, $10-15 \%$ of children will be poorly accepted or rejected by their peers (Parker, Rubin, Erath, Wojslawowicz, $\&$ Buskirk, 2006). More seriously, a similar percentage (13\% to $20 \%$ or more depending on sample) of 11 year old school 
children report being a victim of bullying at least twice in the past month (Currie et al., 2012).

In addition to adverse experiences with peers, troubled relationships with teachers are also sources of risk for children's development. Indeed, to be effective instructors, teachers must connect with and care for children with warmth, respect, and trust. Unfortunately, not all children have warm relationships with teachers, and problems in this relationship are linked with child maladjustment (Bergin \& Bergin, 2009; Thapa, Cohen, Guffey, \& Higgins-D'Alessandro, 2013). There is an abundance of evidence showing that adverse social experiences with peers and teachers during the elementary school period are linked to serious negative outcomes, including symptoms of externalizing and internalizing problems, suicidal thoughts and acts with hospitalization, academic underachievement, physical illness and poor self-perceptions (Cillessen \& Lansu, 2015; Deater-Deckard, 2001; Hamre \& Pianta, 2005; Klomek, Marrocco, Kleinman, Shonfeld, \& Gould, 2007, Klomek et al., 2009; McDougall \& Vaillancourt, 2015; Parker et al., 2006; van Lier \& Koot, 2010; Wang, Selman, Dishion, \& Stormshak, 2010). Despite the accumulating evidence of the role of adverse social experiences on child maladjustment outcomes, knowledge about the impact of such school social experiences on children's executive functions is limited, particularly with respect to childhood. This is a serious omission in the literature.

Executive functions in this special section are defined as a 'general-purpose control mechanisms, often linked to the prefrontal cortex of the brain, that regulate the dynamics of human cognition and action' (Miyake \& Friedman, 2012; p. 8). It includes three major sub-domains: inhibitory control, working memory, and attention/set shifting (Miyake \& Friedman, 2012). Apart from studying executive functions in their own right, understanding the impact of aversive social experiences on cognitive functions may address the connection between such social experiences and social-emotional maladjustment outcomes as described above.

Empirical studies on the impact of adverse social experiences such as rejection or exclusion by peers have shown that rejection indeed may affect executive functions. For instance, social exclusion is linked with poorer response inhibition (Gomes \& Livesey, 2008; Snyder, Prichard, Schrepferman, Patrick, \& Stoolmiller, 2004) and working memory (Hawes et al., 2012). However, with some exceptions (e.g., Hawes et al., 2012), this small literature is based primarily on samples spanning late childhood through adulthood. Given that children may experience social rejection swiftly after the transition to formal schooling (Gooren, van Lier, Stegge, Terwogt, \& Koot, 2011; Snyder, Horsch, \& Childs, 1997), and given that the impact of such early rejection is particularly profound during these early years (Ladd, 2006), there is a need to examine the links with executive functions earlier in development. Another limitation of the existing literature is that it relies heavily on laboratory experiments, not naturalistic studies of children followed in their real social experiences. Therefore, the broad objective of the current special section was to study the links between school social experiences and children's executive function development among children who were first assessed during the kindergarten or early years of elementary school.

\section{Relationships with Peers and Executive Function Development}

There are several theoretical notions explaining links between relationships with peers and children's executive function development. For instance, regulatory depletion theory stresses that stress in the regulation of social stress results in depletion of resources, thereby impairing cognitive functions (Davies, Woitach, Winter, \& Cummings, 2008). Similarly, according to Williams (Williams, 2001, 2007), the human responses to adverse social experiences like social rejection start with a reflective painful response, followed by threats to the need to belong, self-esteem, need to control, and need for a meaningful existence. Baumeister, Twenge, and Nuss (2002) proposed that the efforts to suppress the distress associated with such experiences result in monopolizing the executive functions necessary for effortful cognitive operations. Not only may such threats to the need to belong directly affect children's executive functioning, the typical response of children following social exclusion will be to mitigate the stress associated with the experience of these troubling social relations (Williams, 2009). The efforts of children to restore good social relationships may further use up cognitive resources. When unsuccessful, children eventually will give up, thereby limiting children's opportunities to interact with peers or to receive stimulation by teachers, which leads to further cognitive function impairment.

This latter part of the possible consequences of troublesome relations with peers highlights the importance of social interactions, or play with peers during the childhood years, which has been highlighted by Coplan and Arbeau (2009). Interactions with peers have been shown to be an essential ingredient in the development of self-regulation (Lindsey \& Colwell, 2003), to develop executive functions such as inhibiting impulsive responses (Peterson \& Flanders, 2005), and to develop cognitive flexibility in response to social play that rewards children for trying out new things (Bateson, 2005).

Two studies in the current special section focus on the role of peers on children's cognitive development. Holmes, KimSpoon, and Deater-Deckard (this issue) have used a composite score for executive function, including measures of inhibitory control, working memory, and attention. Children were followed across three waves from 4.5 to 15 years. In line with 
previous studies, the authors found that lower performance of executive functions predicted increases in peer problems across the studied period. However, and limited to childhood, they also found that peer problems hampered executive function development. In the study by Wilde, Koot, and van Lier (this issue), children were followed across three waves covering the early school years. Links between children's working memory and their relations with peers (and teachers) were investigated. Although links from working memory and peer likeability were found - indicating the lower working memory abilities predicted decreases in children's likeability - no reverse paths from peer experiences to children's working memory development were found. However, links between experiences with teachers and children's working memory development were found, as described later.

The study by Will, van Lier, Crone, and Güroğlu (this issue) deserves particular attention because of its inclusion of measures of brain activity during social exclusion. In this study, children were annually assessed on their social preference (ratio between like and dislike nominations among classmates) across elementary school. Using the average social preference scores across the entire elementary school period, the authors selected children scoring at the lower 10th (chronically rejected) and upper 10th (stable accepted) percentile. These children were subsequently invited to participate in an fMRI study, when these children were on average 14 years of age. In the fMRI, the adolescents with a history of chronic rejection or stable acceptance during elementary school were subjected to Cyberball social exclusion/inclusion (Williams \& Jarvis, 2006). The results showed that rejected children compared to accepted children showed heightened activation of the dorsal anterior cingulate cortex (dACC) during social exclusion. Moreover, during the inclusion condition of Cyberball, children were occasionally excluded but then included in the ball tossing. Results showed that adolescents with a history of rejection, compared to their socially accepted counterparts, showed increased activation of the dACC and anterior prefrontal cortex (PFC) following such incidental experiences of exclusion. Activation in these regions have been linked to conflict monitoring, expectation violations, physical pain, and social inclusion (Botvinick, Cohen, \& Carter, 2004; Eisenberger, Lieberman, \& Williams, 2003; Shenhav, Botvinick, \& Cohen, 2013; Somerville, Heatherton, \& Kelley, 2006). Moreover, higher activation of the dACC and PFC have been linked to rejection sensitivity (Masten et al., 2009). Therefore, these results may underscore that children's and adolescents' histories of manifest rejection by classmates makes them sensitive to new experiences of rejection or social exclusion even at the neural activation level of analysis.

Collectively the results of these papers advance previous work on the impact of social experiences with peers on children's executive functions. The results confirm previously discovered links with executive functions facilitating or hampering social relations with classmates, but the findings also suggest a dynamic interplay between peer processes and executive function skills. Note that the study by Wilde, Koot, and van Lier (this issue) did not find paths from peer processes to working memory. However, this study mostly focused on positive aspects of peer relationships (i.e., likeability and having friends). It may well be, as suggested by the study by Holmes, Kim-Spoon, and Deater-Deckard (this issue), that the impact of negative experiences on children's development is more profound that the impact of positive experiences (Baumeister, Bratslavsky, Finkenauer, \& Vohs, 2001). The results of the study by Will, van Lier, Crone, and Güroğlu (this issue) seem to be in line with this. Indeed, although that study did not control for possible existing group differences in neural activity prior to elementary school entry, the specific differences in neural responses that logically correspond with rejection sensitivity suggest that it was the social experience that these children encountered - specifically, a history of prolonged rejection versus stable acceptance by peers - that contributed to their differential neural responses in adolescence.

\section{Relationships with Teachers and Executive Function Development}

Models of cognitive depletion or threats to the need to belong may also relate well to the relationship between teachers and children. Indeed, building solid and supportive relations with teachers (as well as peers) has been described as a key component to children's healthy and positive development (Jennings \& Greenberg, 2009). Two studies in this special section have focused on the impact of the teacher child relationship on children's executive functions. The study by Cadima, Verschueren, Leal, and Guedes (this issue) focuses on the impact of teachers at both the dyadic and classroom level on children's self-regulation, measured as attention, working memory and inhibitory control. Children who were on average almost 5 years old were followed across one school year. The authors found that dyadic level teacherchild closeness predicted increases in self-regulation across the school year. Moreover, an interaction between classroom-level teacher instructional quality and children's initial levels of self-regulation was found. Girls (but not boys) with the lowest levels of self-regulation at the beginning of the year increased the most in their self-regulation if exposed to high quality teacher instruction.

The study by Wilde et al. (this issue) also reports the likely impact of the teacher-child relationship, specifically with respect to children's working memory development. They found that teacher-child conflict predicted a less favorable development of working memory skills across the studied period - above and beyond reciprocal paths from working 
memory to teacher-child conflict. No such predictive links were found for teacher-child warmth. All these association were similar for boys and girls.

Again, the papers from this special section extend to the previous literature by showing that in addition to relationships with peers, relationships with teachers play a vital role in the shaping of children's executive function development. The study by Cadima, Verschueren, Leal, and Guedes (this issue) shows that this influence can be at both the dyadic level, and the classroom level among children at highest risk for problems in development. Moreover, the finding that dyadic teacher-child relationship characteristics could affect children's working memory development, beyond possible reverse paths (Wilde et al., this issue), again suggests a dynamic interplay between children's characteristics and their social environment. This is a bidirectional process that has been previously found for other more overt child characteristics such as conduct problems (Mercer \& DeRosier, 2008; Sturaro, van Lier, Cuijpers, \& Koot, 2011).

\section{Conclusion}

The papers in this special section advance our knowledge on the developmental links between school social experiences and children's executive functions in a number of ways. They extend previous work by linking peer and teacherchild relationship characteristics to executive functions in childhood, using rigorously executed longitudinal designs. All papers in this special section used measures of everyday social experiences, measured in the real lives of the children and adolescents. Thus, not only extreme experiences like maltreatment (Beers \& De Bellis, 2002) but also subtle, typical experiences may advance or hamper children's cognitive development at the behavioral and neural levels of analysis. Collectively, the papers in this special section also show that adverse social experiences during the elementary school period seem to affect both executive functions in general (Cadima et al., this issue; Holmes et al., this issue) and specific aspects of executive functions (Wilde et al., this issue).

There is now rapidly growing consensus on the potential hazardous effects of harsh school social environments on children's maladjustment. The papers in this special section add to this by showing how such experiences affect children's executive function development. More effort is needed to understand the dynamic interplay between child characteristics and the child's social environment, including more insights into which characteristics of the child make them more or less susceptible to the impact of such school adverse social experiences. It also urges us to direct research at understanding how school and classroom structures and processes are linked to the development of negative peer experiences. A recent series of papers in this same journal addressed this topic by focusing on how school and classroom factors were linked to bullying perpetration and victimization (Brendgen \& TroopGordon, 2015).

The ultimate goal is to develop programs that prevent children from experiencing adverse social experiences. For instance, classroom management programs have been found effective in improving both classroom peer and teacher-child relations, thereby positively affecting children's outcomes (Leflot, van Lier, Onghena, \& Colpin, 2010; Witvliet, van Lier, Cuijpers, \& Koot, 2009). But the papers in this special section also suggest that such prevention efforts may need to be directed at multiple levels of the school context. Preventing victimization may already be a challenge, but the papers in this section have shown that even more passive processes like peer likeability, and evocative processes in the teacher-child relationship, are influential. Therefore, further investments are required in multi-component programs that encompass elements of systematic monitoring, school policies, classroom management, and dyadic relationship in the classroom. Such programs should also focus on secondary prevention, to help susceptible children who despite the components focusing on facilitating prosocial classroom interaction are nonetheless experiencing the impact of adverse social experiences during the elementary school period. Finally, nesting such preventive intervention programs in a randomized controlled study design may provide us with the critical test of the suggested links between children's social experiences and their executive functions development found by the studies in this special section. Indeed, despite the strengths of the longitudinal designs used, a necessary step in our knowledge on this would be to study using experiments whether the impact of social experiences on children's executive functions is mitigated when prevention is successful in minimizing children's exposure to adverse school social experiences (Howe, Reiss, \& Yuh, 2002; Rutter, 2002, 2003).

\section{Compliance with Ethical Standards}

Conflict of Interest The authors declare that they have no conflict of interest, financial or otherwise.

\section{References}

Bateson, P. (2005). The role of play in the evolution of great apes and humans. New York: Guilfort Press.

Baumeister, R. F., Bratslavsky, E., Finkenauer, C., \& Vohs, K. D. (2001). Bad is stronger than good. Review of General Psychology, 5, 323370. doi:10.1037/1089-2680.5.4.323.

Baumeister, R. F., Twenge, J. M., \& Nuss, C. K. (2002). Effects of social exclusion on cognitive processes: anticipated aloneness reduces intelligent thought. Journal of Personality and Social Psychology, 83(4), 817-827. doi:10.1037/0022-3514.83.4.817. 
Beers, S. R., \& De Bellis, M. D. (2002). Neuropsychological function in children with maltreatment-related posttraumatic stress disorder. American Journal of Psychiatry, 159, 483-486.

Bergin, C., \& Bergin, D. (2009). Attachment in the classroom. Educational Psychology Review, 21(2), 141-170.

Botvinick, M. M., Cohen, J. D., \& Carter, C. S. (2004). Conflict monitoring and anterior cingulate cortex: an update. Trends in Cognitive Sciences, 8, 539-546.

Brendgen, M., \& Troop-Gordon, W. (2015). School-related factors in the development of bullying perpetration and ictimization: introduction to the special section. Journal of Abnormal Child Psychology, 43(1), $1-4$.

Cadima, J., Verschueren, K., Leal, T., \& Guedes, C. (this issue). Classroom interactions, dyadic teacher-child relationships and selfregulation in socially disadvanced young children. Journal of Abnormal Child Psychology.

Cillessen, A. H. N., \& Lansu, T. A. M. (2015). Stability, correlates, and time-covarying associations of peer victimization from grade 4 to 12. Journal of Clinical Child and Adolescent Psychology, 44(3), 456-470.

Coplan, R. J., \& Arbeau, K. A. (2009). Peer interactions and play in early childhood. New York: Guilford Press.

Currie, C., Zanotti, C., Morgan, A., Currie, D., de Looze, M., Roberts, C., et al. (2012). Social determinants of health and well-being among young people, Health behaviour in school-aged children (HBSC) study: International report from the 2009/2010 survey. (6). Copenhagen: WHO Regional Office for Europe.

Davies, P. T., Woitach, M. J., Winter, M. A., \& Cummings, E. M. (2008). Children's insecure representations of the interparental relationship and their school adjustment: the mediating role of attention difficulties. Child Development, 79, 1570-1582. doi:10.1111/j.1467-8624. 2008.01206.x.

Deater-Deckard, K. (2001). Annotation: recent research examining the role of peer relationships in the development of psychopathology. Journal of Child Psychology and Psychiatry, 42(5), 565-579.

Eisenberger, N. I., Lieberman, M. D., \& Williams, K. D. (2003). Does rejection hurt? An FMRI study of social exclusion. Science, 302(5643), 290-292. doi:10.1126/science.1089134.

Gomes, L., \& Livesey, D. (2008). Exploring the link between impulsivity and peer relations in 5-and 6-year- old children. Child Care Health and Development, 34(6), 763-770. doi:10.1111/j.1365-2214.2008. 00878.x.

Gooren, E., van Lier, P. A. C., Stegge, H., Terwogt, M. M., \& Koot, H. M. (2011). The development of conduct problems and depressive symptoms in early elementary school children: the role of peer rejection. Journal of Clinical Child and Adolescent Psychology, 40(2), 245-253. doi:10.1080/15374416.2011.546045.

Hamre, B. K., \& Pianta, R. C. (2005). Can instructional and emotional support in the first-grade classroom make a difference for children at risk of school failure? Child Development, 76(5), 949-967.

Hawes, D. J., Zadro, L., Fink, E., Richardson, R., O’Moore, K., Griffiths, B., et al. (2012). The effects of peer ostracism on children's cognitive processes. European Journal of Developmental Psychology, 9(5), 599-613. doi:10.1080/17405629.2011.638815.

Holmes, C.J., Kim-Spoon, J., \& Deater-Deckard, K. (this issue). Linking executive fuctions and peer problems from early childhood to middle adolescence. Journal of Abnormal Child Psychology.

Howe, G. W., Reiss, D., \& Yuh, J. (2002). Can prevention trials test theories of etiology? Development and Psychopathology, 14(4), 673-694.

Jennings, P. A., \& Greenberg, M. T. (2009). The prosocial classroom: teacher social and emotional competence in relation to student and classroom outcomes. Review of Educational Research, 79(1), 491525. doi:10.3102/0034654308325693.

Klomek, A. B., Marrocco, F., Kleinman, M., Shonfeld, I. S., \& Gould, M. S. (2007). Bullying, depression and suicidality in adolescents.
Journal of the American Academy of Child and Adolescent Psychiatry, 46(1), 40-47.

Klomek, A. B., Sourander, A., Niemela, S., Kumpulainen, K., Piha, J., Tamminen, T., et al. (2009). Childhood bullying behaviors as a risk for suicide attempts and completed suicides: a population-based birth cohort study. Journal of the American Academy of Child and Adolescent Psychiatry, 48(3), 254-261.

Ladd, G. W. (2006). Peer rejection, aggressive or withdrawn behavior, and psychological maladjustment from ages 5 to 12 : an examination of four predictive models. Child Development, 77(4), 822-846.

Ladd, G. W., Herald, S. L., \& Kochel, K. P. (2006). School readiness: are there social prerequisites? Early Education and Development, 17, $115-150$.

Leflot, G., van Lier, P. A., Onghena, P., \& Colpin, H. (2010). The role of teacher behavior management in the development of disruptive behaviors: An intervention study with the Good Behavior Game. Journal of Abnormal Child Psychology, 38(6), 869-882. doi:10. 1007/s10802-010-9411-4.

Lindsey, E. W., \& Colwell, M. J. (2003). Preschoolers' emotional competence: links to pretend and physical play. Child Study Journal, 33, $39-52$.

Masten, C. L., Eisenberger, N. I., Borofsky, L. A., Pfeifer, J. H., McNealy, K., Mazziotta, J. C., \& Dapretto, M. (2009). Neural correlates of social exclusion during adolescence: understanding the distress of peer rejection. Social Cognitive and Affective Neuroscience, 4(2), 143-157. doi:10.1093/scan/nsp007.

McDougall, P., \& Vaillancourt, T. (2015). Long-term adult outcomes of peer victimization in childhood and adolescence: pathways to adjustment and maladjustment. American Psychologist, 70(4), 300310.

Mercer, S. H., \& DeRosier, M. E. (2008). Teacher preference, peer rejection, and student aggression: a prospective study of transactional influence and independent contributions to emotional adjustment and grades. Journal of School Psychology, 46, 661-685.

Miyake, A., \& Friedman, N. P. (2012). The nature and organization of individual differences in executive functions four general conclusions. Current Directions in Psychological Science, 21, 8-14.. doi: 10.1177/0963721411429458.

Parker, J., Rubin, K. H., Erath, S., Wojslawowicz, J. C., \& Buskirk, A. A. (2006). Peer relationships and developmental psychopathology. In D. Cicchetti, \& D. Cohen (Eds.), Developmental psychopathology: risk, disorder, and adaptation (vol. 2, 2nd ed., pp. 419-493). New York: Wiley.

Peterson, J. B., \& Flanders, J. L. (2005). Play and the regulation of aggression. New York: Guilford Press.

Rutter, M. (2002). Development and psychopathology. In M. Rutter, \& A. Taylor (Eds.), Child and adolescent psychiatry, fourth edition. Oxford: Blackwell Science.

Rutter, M. (2003). Commentary: causal processes leading to antisocial behavior. Developmental Psychology, 39(2), 372-378.

Shenhav, A., Botvinick, M. M., \& Cohen, J. D. (2013). The expected value of control: an integrative theory of anterior cingulate cortex function. Neuron, 79, 217-240.

Snyder, J., Horsch, E., \& Childs, J. (1997). Peer relationships of young children: affiliative choices and the shaping of aggressive behavior. Journal of Clinical Child Psychology, 26, 145-156.

Snyder, J., Prichard, J., Schrepferman, L., Patrick, M. R., \& Stoolmiller, M. (2004). Child impulsiveness-inattention, early peer experiences, and the development of early onset conduct problems. Journal of Abnormal Child Psychology, 32(6), 579-594.

Somerville, L. H., Heatherton, T. F., \& Kelley, W. M. (2006). Anterior cingulate cortex responds differentially to expectancy violation and social rejection. Nature Neuroscience, 9, 1007-1008.

Sturaro, C., van Lier, P. A. C., Cuijpers, P., \& Koot, H. M. (2011). The role of peer relationships in the development of early school-age externalizing problems. Child Development, 82(3), 758-765. 
Thapa, A., Cohen, J., Guffey, S., \& Higgins-D’Alessandro, A. (2013). A review of school climate research. Review of Educational Research, 83(3), 357-385.

van Lier, P. A. C., \& Koot, H. M. (2010). Developmental cascades of peer relations and symptoms of externalizing and internalizing problems from kindergarten to fourth-grade elementary school. Development and Psychopathology, 22(3), 569-582.

Wang, M. T., Selman, R. L., Dishion, T. J., \& Stormshak, E. A. (2010). A tobit regression analysis of the covariation between middle school students' perceived school climate and behavioral problems. Journal of Research on Adolescence, 20(2), 274-286.

Wilde, A., Koot, J.M., \& van Lier, P.A.C. (this issue). Developmental links between children's working memory and their social relations with teachers and peers in the early school years. Journal of Abnormal Child Psychology.

Will, G.J., van Lier, P.A.C., Crone, E.A., \& Güroğlu, B. (this issue). Chronic childhood peer rejection is associated with heightened neural responses to social exclusion during adolescence. Journal of Abnormal Child Psychology.

Williams, K. D. (2001). Ostracism: The power of silence. New York: Guilford Publications.

Williams, K. D. (2007). Ostracism. Annual Review of Psychology, 58, 425-452.

Williams, K.D. (2009). Ostracism: A temporal need-threat model. In M.P. Zanna (Ed.), Advances in Experimental Social Psychology, Vol 41 (Vol. 41, pp. 275-314).

Williams, K. D., \& Jarvis, B. (2006). Cyberball: a program for use in research on interpersonal ostracism and acceptance. Behavior Research Methods, 38, 174-180.

Witvliet, M., van Lier, P. A., Cuijpers, P., \& Koot, H. M. (2009). Testing links between childhood positive peer relations and externalizing outcomes through a randomized controlled intervention study. Journal of Consulting and Clinical Psychology, 77(5), 905-915. 